\title{
PREDICTORS OF DEPRESSED LEFT VENTRICULAR FUNCTION IN PATIENTS PRESENTING WITH ST-ELEVATION MYOCARDIAL INFARCTION
}

\author{
Tarek Ahmed Naguib, Eslam Abdel Moneim Elsherbeiny, Ahmad Mohamed AbdelFattah Elzayyat and \\ Ayman Elsayed Mohamed Tantawy* \\ Cardiology Department, Faculty of Medicine, Zagazig University
}

\begin{abstract}
Background: Left ventricular dysfunction after ST segment elevation myocardial infarction (STEMI) is the most important factor affecting morbidity and mortality. The primary objective of reperfusion therapy is to restore epicardial flow and to reperfuse the myocardial tissue. However, in some cases lack of microvascular reperfusion and, consequently, significant left ventricular (LV) dysfunction persist despite the rapid and sustained restoration of blood flow. Early in the course of STEMI, therapies that may harm patients who develop LV dysfunction, such as beta-blockers, are often administered.

Aim of the work: construct a predictive score of the risk of developing left ventricular dysfunction in patients with STEMI.

Patient and methods: This study was done in Cardiology department, Zagazig University on 100 patients; 78 males $(78 \%)$ \& 22 females $(22 \%)$ with first acute STEMI underwent successful primary percutaneous intervention (pPCI). Within 72 hours of admission, all of the following parameters were reported: risk factors, blood pressure, heart rate, KILLIP class, need for mechanical ventilation (MV), cardiac enzymes, admission blood sugar, kidney function, lipid profile, electrocardiographic data (ST elevation in millimeters $(\mathrm{mm})$, location of infarction, ST resolution, QRS width in milliseconds (ms), Selvester score), echocardiography (ejection fraction by Simpson's method, wall motion score index) and angiographic data (culprit artery, Total number of diseased vessels, severity of coronary artery disease, Gensini score and door to balloon time).

Results: LV dysfunction was associated with decreased renal function (creatinine $>1.1 \mathrm{mg} / \mathrm{dl}, \mathrm{p}=0.029$ ), number of diseased vessels $>2(\mathrm{p}=0.034)$, absence of complete ST segment resolution $(\mathrm{p}<0.001)$, wall motion score index $>2.05$ $(\mathrm{p}=0.008)$, sum of ST segment elevation $>13.5 \mathrm{~mm}(\mathrm{p}<0.001)$, QRS width $>98.5 \mathrm{~ms}(\mathrm{p}<0.001)$, Selvester score $>3.5$ $(\mathrm{p}<0.001)$ Gensini score $>95(\mathrm{p}<0.001)$, anterior location of infarction $(\mathrm{p}=0.002)$ and KILLIP class $>1(p=0.003)$. A prediction score using these variables stratified patients into low, intermediate and high-risk groups for LV dysfunction; positive likelihood ratios for LV dysfunction in these groups were 2.9, 2.1, and 2.4, respectively.

Conclusions: 10 key predictors of in-hospital LV dysfunction after STEMI were identified; a risk score based on these predictors helps to quickly identify patients presenting with STEMI who are at the highest risk for developing significant LV dysfunction and could guide optimal therapeutic choices.
\end{abstract}

Key words: ST-elevation myocardial infarction, left ventricular dysfunction, predictors, score, primary angioplasty.

\section{INTRODUCTION}

A lthough the incidence of ST-segment elevation myocardial infarction (STEMI) has decreased over the past decade, it remains a common and morbid diagnosis [1].

It is a life-threatening situation, rapid and correct decision making for life saving of patients in emergency room is very important [2].

Primary treatment for patients with acute STEMI is fibrinolysis or primary angioplasty. The use of primary PCI has improved the outcome of STEMI patients significantly [3].

Ischemic heart disease is the most common contributor to left ventricular dysfunction. The extent of left ventricular (LV) function varies considerably among patients with extensive coronary disease, and clinical and angiographic factors associated with LV impairment are poorly characterized. Specifically, whether clinical, demographic and angiographic characteristics differ among patients and are predictive of LV ejection fraction has not been determined [4].

Despite aggressive primary therapy, prognosis remains poor in patients with large infarctions and severe left ventricular (LV) dysfunction [5].

Early in the course of ST-segment elevation myocardial infarction (STEMI), therapies that may harm patients who develop left ventricular (LV) dysfunction are often administered. Early identification, preferably in the emergency department (ED), of patients at highest risk for developing left ventricular (LV) dysfunction could serve to inform the use of certain therapies [6].

\section{AIM OF THE WORK}

The present study aimed to construct a predictive score of the risk of developing left ventricular dysfunction in patients with ST segment elevation myocardial infarction.

\section{PATIENTS AND METHODS}

This study was carried out in Zagazig University Hospitals; it was conducted from January 2012 to August 2013. It included (100) patients admitted with first acute ST segment elevation myocardial infarction (STEMI). Informed consent obtained from every patient on 
participation of the study. Medical research and ethics committee approved the study.

\section{Inclusion Criteria:}

Patients with first acute STEMI. STEMI was diagnosed by elevation of cardiac biomarkers associated with symptoms of ischemia and a new ST elevation, presumed new onset left bundle branch block (LBBB) or pathological Q waves.

ST-segment elevation was defined as J-point elevation in 2 contiguous leads of $2 \mathrm{~mm}$ in leads $\mathrm{V} 1, \mathrm{~V} 2$, or V3 and $1 \mathrm{~mm}$ in other leads. STsegment depression $1 \mathrm{~mm}$ in leads V1 to V3, consistent with a posterior STEMI was also considered ST-segment elevation [6].

Those with previous history of coronary artery disease other than previous myocardial infarction were also included in the study group.

\section{Exclusion criteria:}

Patients with previous Myocardial infarction, Previous diagnosis of heart failure, Pre-existing significant valvular heart disease, Patients with old left bundle branch block (LBBB), those who did not do echocardiography during the index STEMI (within 72 hours of admission) or those whom it was difficult to delineate the endocardial border by Simpson's method, Patients with instent restenosis, Patients with previous CABG.

Grouping the patients: Patients were divided according to the ejection fraction (EF) by echocardiography in to 2 groups: Group (I): 36 patients with $\mathrm{EF} \leq 40 \%$, Group (II): 64 patients with $\mathrm{EF}>40 \%$

All patients were subjected to all of the following:

A) Complete history taking.

B) Thorough physical examination including.

C) Resting 12-lead standard surface electrocardiogram:

STEMI was diagnosed according to the following: New ST segment elevation at J-point in $\geq 2$ contiguous leads of $\geq 2 \mathrm{~mm}$ in leadsV1, V2, or
$\mathrm{V} 3$ and $\geq 1 \mathrm{~mm}$ in other leads. ST-segment depression $\geq 1 \mathrm{~mm}$ in leads V1 to V3, consistent with a posterior STEMI, was considered as STsegment elevation[6]. ST segment elevation, measured $20 \mathrm{~ms}$ after the $\mathrm{J}$ point. The height (in $\mathrm{mm}$ ) of ST segment elevations was measured in leads I, aVL, and V1 through V6 for anterior infarction; leads II, III, aVF for inferior infarction and leads V5 to V6 for lateral. The sum of all measured ST segment elevations was expressed as STE. Resting ECG was repeated for all patients 90-120 minutes following first balloon inflation, from which the sum of ST segment elevations was measured again. The difference between both was then taken and divided by the initial one. The result then accepted as ST segment elevation resolution (STR) and expressed as a percentage.

STR $=\frac{\text { Initial }(\Sigma \text { STE })-(\Sigma \text { STE }) \text { on the secondECG }}{\text { Initial }(\Sigma \text { STE })}$

Patients were divided into three groups according to the degree of ST-segment resolution: < $30 \%$ (no resolution); $30 \%$ to $70 \%$ (partial resolution); and $>70 \%$ (complete resolution) [7].

QRS width was measured manually using calipers. The lead recording the widest QRS was used for the analysis. Development of atrial fibrillation or ventricular fibrillations during course of admission was reported for every patient.

Estimating infarction size using simplified Selvester QRS score was applied for discharge ECG. The simplified version of the Selvester QRS scoring system uses 50 weighted analysis of QRS complexes in ten leads (I, II, VL, VF and V1 to V6), totaling a maximum of 31 points. (Table 1). Each point being equivalent to approximately $3 \%$ of the left ventricular mass [8]. 
Table 1: Modified Selvester QRS score [8].

\begin{tabular}{|c|c|c|c|c|c|c|c|c|c|c|c|}
\hline \multicolumn{12}{|c|}{ Complete 50-Criterla, 31-Point QRS Scoring System* } \\
\hline Leed & $\begin{array}{l}\text { Moximum } \\
\text { Loes } \\
\text { Points }\end{array}$ & Crituria & Folnts & $v_{i_{1}}$ Anteriot & (1) & anyo & (1) & $v_{2}$ & (1) & $\begin{array}{l}\text { Any O } \\
A=20 \mathrm{~ms} \\
\text { As0.2 mV }\end{array}$ & $\begin{array}{l}51 \\
11 \\
11 \\
11\end{array}$ \\
\hline 1 & (2) & $\begin{array}{c}\mathrm{C} \times 30 \mathrm{~ms} \\
\left\{\begin{array}{l}\mathrm{RO} O 51 \\
\mathrm{~A}=0.2 \mathrm{mV}\end{array}\right.\end{array}$ & $\begin{array}{l}\text { (1) } \\
\text { (i) } \\
\text { (i) }\end{array}$ & Posteriot & (4) & $\begin{array}{l}\text { AUS } e 1 \\
\qquad \begin{array}{l}A \geq 50 \mathrm{~ms} \\
A \geq 10 \mathrm{mV} \\
R \geq 40 \mathrm{~ms} \\
R \geq 0.5 \mathrm{mV}\end{array}\end{array}$ & $\begin{array}{l}\text { (1) } \\
\text { (12) } \\
\text { (2) } \\
\text { (i) }\end{array}$ & $v_{i}$ & कार & $\begin{array}{l}\text { P.S } 50.5 \\
R O \leq 0.5 \\
R S \leq 5 \\
R O \leq 1 \\
R \leq 0.7 \mathrm{mV}\end{array}$ & $\begin{array}{l}\text { (2) } \\
\text { (2) } \\
\text { i1) } \\
\text { (1) } \\
\text { (1) }\end{array}$ \\
\hline " & (2) & $\mathrm{O}=40 \mathrm{~ms}$ & (2) & & Q an & $\mathrm{S} \approx 0.3 \mathrm{mV}$ & (1) & $v_{s}$ & (3) & $0 \geq 30 \mathrm{~ms}$ & (1) \\
\hline sin & (2) & $\begin{array}{l}\mathrm{Oe}=30 \mathrm{~ms} \\
\mathrm{AOO} \leqslant 1\end{array}$ & (1) & $v_{z_{2}}$ Notiorior & (1) & $\left\{\begin{array}{l}A m y \quad Q \\
R \leq 10 \mathrm{~ms} \\
R \leq Q, 1 \mathrm{mV} \\
\mathrm{A} \leq \mathrm{R} V, \mathrm{mV}\end{array}\right.$ & $\begin{array}{l}\text { (1) } \\
\text { (ii) } \\
\text { (1) } \\
\text { (1) }\end{array}$ & & & $\begin{array}{l}\text { RUS } \leqslant 1 \\
\text { RQ } \leqslant 1 \\
\text { RS } \leqslant 2 \\
\text { RQ } \leqslant 2 \\
R \leqslant 0.7 \mathrm{mV}\end{array}$ & $\begin{array}{l}\text { (2) } \\
\text { (2) } \\
\text { (1) } \\
\text { (1) } \\
\text { (1) }\end{array}$ \\
\hline avr & (5) & $\begin{array}{l}\left\{\begin{array}{l}O=50 \mathrm{~ms} \\
O=40 \mathrm{~ms} \\
O \approx 30 \mathrm{~ms}\end{array}\right. \\
\left\{\begin{array}{l}A Q=1 \\
A O=2\end{array}\right.\end{array}$ & $\begin{array}{l}\text { (3) } \\
\text { (1) } \\
\text { (1) } \\
\text { (2) } \\
\text { (1) }\end{array}$ & Posterior & (4) & $\begin{array}{l}\text { NS } \geq 1 \mathrm{~s} \\
\left(\begin{array}{l}A \geq 60 \mathrm{~ms} \\
\mathrm{R} \geq 2.0 \mathrm{mV} \\
A^{2} \leq 50 \mathrm{~ms} \\
\mathrm{~A} \geq 1.5 \mathrm{mV}\end{array}\right. \\
S \leq 0.4 \mathrm{mV}\end{array}$ & $\begin{array}{l}\text { (1) } \\
\text { (2) } \\
\text { (2) } \\
\text { (1) } \\
\text { (1) } \\
\text { (1) }\end{array}$ & $v_{6}$ & (3) & $\begin{array}{l}Q>30 \mathrm{~ms} \\
\\
\text { RS } \leq 1 \\
A D=1 \\
R S \leq 3 \\
R O \leq 3 \\
A \leqslant 0.8 \mathrm{mV}\end{array}$ & $\begin{array}{l}\text { [1] } \\
\text { (2) } \\
\text { (2) } \\
11 \\
11 \\
11\end{array}$ \\
\hline
\end{tabular}

\section{D) Laboratory investigations:}

Blood samples for total CK, CK-MB were collected, peak values were taken for each of them in $1^{\text {st }} 24$ hours. Troponin $\mathrm{T}(\mathrm{cTn})$ was considered positive if it exceeds the 99th percentile of normal reference (above $0.035 \mathrm{ng} / \mathrm{mL}$ ), Random blood sugar on admission, Kidney functions with special emphasis on creatinine level, Lipid profile measured after 12 hours of fasting including cholesterol, triglyecerides (TG), high density lipoprotein(HDL) and low density lipoprotein(LDL).

\section{E) Echocardiography}

All patients underwent two dimensional (2D) echocardiography during index hospitalization in first 72 hours using (Hewlette Packard) Sonos 5500 set. Recordings and calculations of different parameters were performed according to the recommendations of the American Society of Echocardiography [9]. The main outcome was calculation of ejection fraction (EF) using the biplane Simpson's method. Both left ventricle end diastolic (LVED) and end systolic (LVES) volumes in apical four chamber (A4C) and apical two chamber (A2C) views were measured.(Figure 1) The EF was then calculated using the following formula for each view:

$$
\mathrm{EF}(\%)=[(\mathrm{EDV}-\mathrm{ESV}) / \mathrm{EDV}] \times 100 \text { [9] }
$$

The mean of the two readings (the biplane) ejection fraction was then taken. The cutoff point of $40 \%$ was chosen before the analysis; $40 \%$ represents a clinically meaningful delineation between mild LV dysfunction (or normal LV function) and moderate to severe LV dysfunction[6]. 


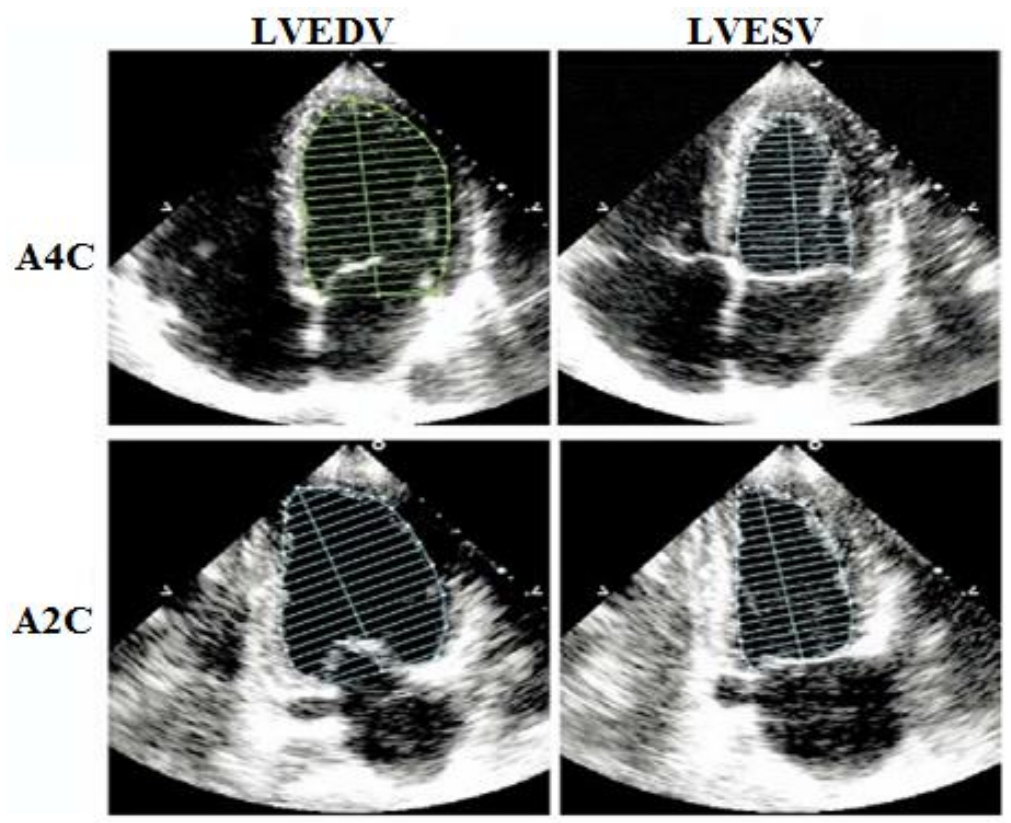

Figure 1: Method of calculation of biplane Simpson method [9].

Visual semi quantitative assessment of regional wall motion and thickening for WMSI was performed. We used the 16-segment model recommended by the ASE [10]. The score for each segment was graded according to the following system: normal, 1; hypokinesia, 2; akinesia, 3; dyskinesia, 4. The total wall motion score (WMS) was obtained by adding the score for each segment. The WMSI was calculated by dividing the total wall motion score by 16 , as shown in Figure 2 .

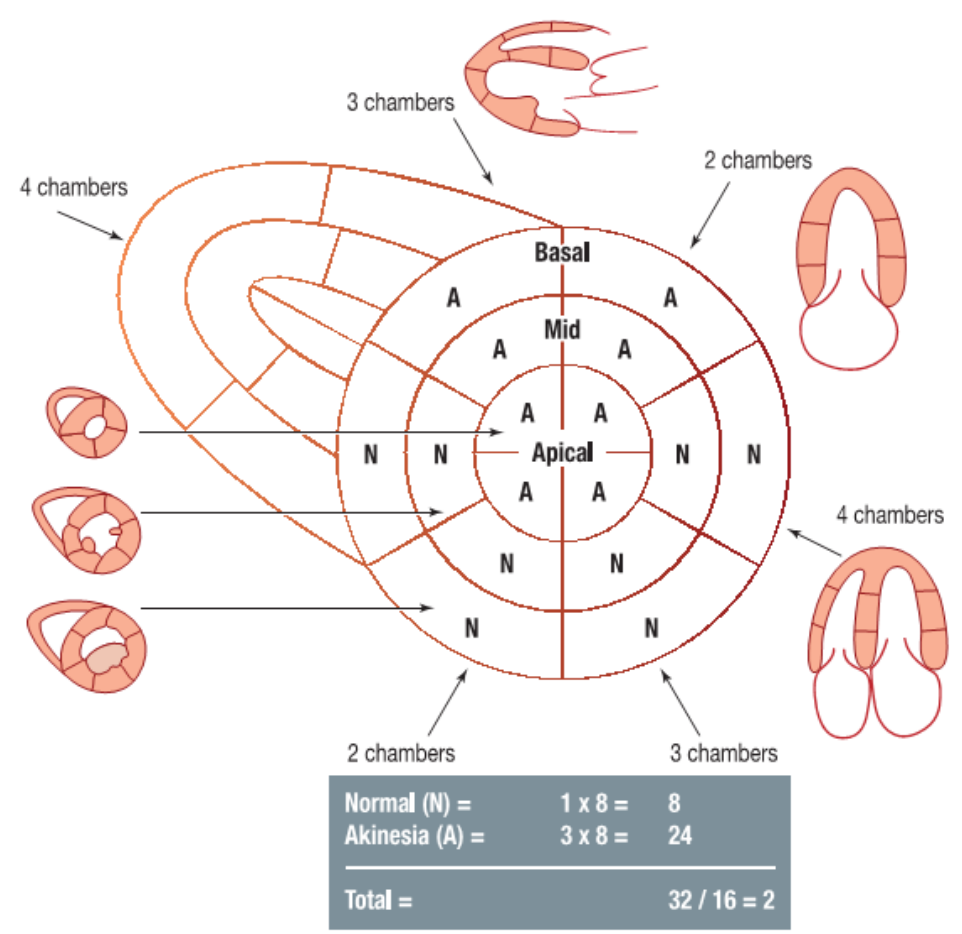

Figure 2: Wall motion score index calculation. If a patient has eight normal segments and eight akinetic segments the wall motion score would be calculated as 32 and the wall motion score index would be $32 / 16=2[\mathbf{1 1}]$.

\section{F) Coronary Angioplasty:}

All patients transferred directly to cath lab in a timely fashion in accordance with guidelines, the door to balloon time (DBT) was calculated. All patients received chewable aspirin $300 \mathrm{mg}$ and clopidogrel $600 \mathrm{mg}$ before the procedure. 
Coronary angiography was done in the standard fashion; the common femoral artery was punctured using seldinger's technique. Coronary angiography was performed in multiple projections for adequate analysis of target lesions. Export aspiration catheter for thrombus aspiration then drug eluting stent (Endeavor resolute integrity) was put either after balloon dilatation or directly only in IRA [12].

Total number of vessels having lesions as well as number of total occlusions other than culprit one were calculated. Coronary lesions other than culprit one were considered significant if any stenosis of $\geq 70 \%$ in at least one major epicardial coronary artery. For left main (LM), lesion $\geq 50 \%$ was considered significant. The extent of coronary atherosclerosis was assessed by the modified Gensini score [13]. In this score, angiographic coronary artery disease extension points calculated from stenosis score $\times$ segment score in 8 coronary segments [14]. Table 2

Table 2: Modified Gensini risk score [14].

\begin{tabular}{cc}
\hline Segment & Score \\
\hline LM & 5 \\
LAD & 20 \\
LCX & 20 \\
RCA & 20 \\
D $_{1}$ & 10 \\
OM 1 & 10 \\
PDA $_{1}$ & 10 \\
S $_{1}$ & 5 \\
\hline Stenosis Percentage & Score \\
\hline $1-49$ & 1 \\
$50-74$ & 3 \\
$75-99$ & 4 \\
\hline
\end{tabular}

\section{Statistical analysis}

All statistical data were processed using the IBM SPSS 19 software. Data were expressed as mean \pm standard deviation (SD). Student t-test, and chi-square test were used to compare the variables. Correlations between the ejection fraction and other parameters were analyzed. A stepwise multivariate analysis was done for independent variables. Odds ratios and 95\% confidence intervals were also calculated. A P value of less than 0.05 was considered significant. A prediction score was developed to provide a schema for the assessment of a patient's likelihood of having depressed LV function using variables readily accessible during patient admission. Key predictors from the multivariate logistic regression as well as likely significant confounders based on clinical knowledge were included in the prediction score. Cutoffs were established with the design of maximizing the sensitivity of the prediction score. Fit was assessed using a receiver-operating characteristic curve.

\section{RESULTS}

The patients were divided according to ejection fraction (EF) by echocardiography in to 2 groups: Group (I): 36 patients with $\mathrm{EF} \leq 40 \%$, Group (II): 64 patients with EF > 40\%. 
Table 3: Demographic and clinical data in the study groups (I\&II) according to ejection fraction.

\begin{tabular}{|c|c|c|c|c|}
\hline \multicolumn{2}{|c|}{ Variable } & Group I $(n)=36$ & Group II $(n)=64$ & P-Value \\
\hline \multicolumn{2}{|c|}{ Age $(\chi \pm$ SD $)$} & $54.1 \pm 10.2$ & $51.7 \pm 8.1$ & $0.234 \mathrm{NS}$ \\
\hline \multirow{2}{*}{$\begin{array}{l}\text { Gender } \\
\text { n }(\%)\end{array}$} & Female & $10(27.8 \%)$ & $12(18.8 \%)$ & \multirow{2}{*}{$0.2 \mathrm{NS}$} \\
\hline & Male & $26(72.2 \%)$ & $52(81.2 \%)$ & \\
\hline \multicolumn{2}{|c|}{ HTN n $(\%)$} & $15(41.7 \%)$ & $34(53.1 \%)$ & $0.2 \mathrm{NS}$ \\
\hline \multicolumn{2}{|c|}{ Known DM n (\%) } & $22(61.1 \%)$ & $37(57.8 \%)$ & 0.7 \\
\hline \multicolumn{2}{|c|}{ Smoker n (\%) } & $14(38.9 \%)$ & $30(46.9 \%)$ & $0.4 \quad \mathrm{NS}$ \\
\hline \multicolumn{2}{|c|}{ Dyslipidemia n (\%) } & $21(58.3 \%)$ & $40(62.5 \%)$ & 0.6 \\
\hline \multicolumn{2}{|c|}{ CAD history n (\%) } & $10(27.8 \%)$ & $17(26.6 \%)$ & $0.89 \mathrm{NS}$ \\
\hline \multicolumn{2}{|c|}{$\operatorname{SBP}(\chi \pm$ SD $)$} & $130.03 \pm 16.9$ & $131.61 \pm 20.69$ & $0.680 \mathrm{NS}$ \\
\hline \multicolumn{2}{|c|}{$\operatorname{DBP}(\chi \pm$ SD $)$} & $80.42 \pm 10.72$ & $82.58 \pm 13.1$ & $0.375 \mathrm{NS}$ \\
\hline \multicolumn{2}{|c|}{ Heart rate $(\chi \pm \mathrm{SD})$} & $76.03 \pm 13.84$ & $73.34 \pm 14.22$ & $0.360 \mathrm{NS}$ \\
\hline \multirow{2}{*}{$\begin{array}{c}\text { KILLIP class } \\
\text { n }(\%)\end{array}$} & $\mathbf{I}$ & $19(52.8 \%)$ & $52(81.2 \%)$ & \multirow{2}{*}{$0.003 *$} \\
\hline & II & $17(47.2 \%)$ & $12(18.2 \%)$ & \\
\hline \multicolumn{2}{|c|}{ Need for MV n (\%) } & $19(52.8 \%)$ & $2(3.1 \%)$ & $0.001 * *$ \\
\hline
\end{tabular}

$\mathbf{n}=$ Number, $\boldsymbol{\chi}=$ mean, $\mathbf{S D}=$ standard deviation, $\mathbf{M V}=$ mechanical ventilation, $\mathbf{N S}=$ non- significant, $*$ significant, $* *$ highly significant

Table 4: Electrocardiographic data in the study groups (I\&II) according to ejection fraction.

\begin{tabular}{|c|c|c|c|c|}
\hline \multicolumn{2}{|c|}{ Variable } & Group I $(n)=36$ & Group II (n) = 64 & P-Value \\
\hline \multicolumn{2}{|c|}{ Max. ST elevation (mm) $(\chi \pm$ SD) } & $17 \pm 4.7$ & $12.6 \pm 4.4$ & 0.00 ** \\
\hline \multicolumn{2}{|c|}{ QRS width $(\mathrm{ms})(\chi \pm$ SD) } & $104 \pm 7.5$ & $88.23 \pm 14.7$ & $0.00 * *$ \\
\hline \multicolumn{2}{|c|}{ Selvester score $(\chi \pm$ SD $)$} & $5.4 \pm 1.6$ & $2.9 \pm 1.5$ & $0.00 * *$ \\
\hline \multirow{3}{*}{$\begin{array}{l}\text { Location of } \\
\text { infarction } \\
\quad \mathbf{n}(\%)\end{array}$} & Anterior & $25(69.5 \%)$ & $18(28.1 \%)$ & \multirow{3}{*}{$0.002^{*}$} \\
\hline & Inferior & $11(30.6 \%)$ & $41(64.1 \%)$ & \\
\hline & Antero-lateral & $0(0 \%)$ & $5(7.8 \%)$ & \\
\hline \multirow{3}{*}{ STR n $(\%)$} & Complete & $2(5.6 \%)$ & $50(78.1 \%)$ & $0.00 * *$ \\
\hline & Partial & $30(83.3 \%)$ & $14(21.9 \%)$ & $0.00 * *$ \\
\hline & Absent & $4(11.1 \%)$ & $0(0 \%)$ & $0.006^{*}$ \\
\hline \multicolumn{2}{|c|}{$\operatorname{AF} n(\%)$} & $0(0 \%)$ & $0(0 \%)$ & - \\
\hline \multicolumn{2}{|c|}{ VF n (\%) } & $4(11.1 \%)$ & $2(3.1 \%)$ & $0.1 \mathrm{NS}$ \\
\hline
\end{tabular}

$\mathbf{S T R}=$ ST segment resolution, $\mathbf{m s}=$ milliseconds, $\mathbf{A F}=$ atrial fibrillation, $\mathbf{V F}=$ Ventricular fibrillation .

Table 5: Laboratory data in the study groups (I\&II) according to ejection fraction.

\begin{tabular}{|c|c|c|c|}
\hline \multirow{2}{*}{ Variable } & Group I $(n)=36$ & Group II $(n)=64$ & \multirow{2}{*}{ P-Value } \\
\hline & $\chi \pm \mathrm{SD}$ & $\chi \pm \mathrm{SD}$ & \\
\hline Peak CK-MB (ng/ml) & $166.5 \pm 71.2$ & 186.12 & $0.15 \mathrm{NS}$ \\
\hline Troponin (ng/ml) & $2.98 \pm 2.5$ & $2.7 \pm 2.35$ & $0.63 \mathrm{NS}$ \\
\hline Creatinine (mg/dl) & $1.2 \pm 0.5$ & $0.95 \pm 0.34$ & $0.007 *$ \\
\hline Cholesterol (mg/dl) & $176.4 \pm 48.8$ & $185.9 \pm 48.7$ & $0.35 \mathrm{NS}$ \\
\hline TG $(\mathrm{mg} / \mathrm{dl})$ & $118.9 \pm 54.99$ & $144.8 \pm 111.2$ & $0.19 \mathrm{NS}$ \\
\hline HDL (mg/dl) & $38.9 \pm 7.8$ & $38.9 \pm 7.96$ & $0.96 \mathrm{NS}$ \\
\hline LDL (mg/dl) & 108.62 & $108.3 \pm 32.2$ & $0.96 \mathrm{NS}$ \\
\hline RBS (mg/dl) & $200.48 \pm 91.3$ & $195.9 \pm 85.6$ & $0.81 \mathrm{NS}$ \\
\hline
\end{tabular}

HDL: high density lipoprotein, LDL: Low density lipoprotein, CK-MB: creatine kinase myocardial band,

RBS: random blood sugar 
Table 6: Echocardiographic data the in study groups

\begin{tabular}{cccc}
\hline \multirow{2}{*}{ Variable } & Group I (n)=36 & Group II (n) = 64 & \multirow{2}{*}{ P-Value } \\
\cline { 2 - 4 } & $(\chi \pm \mathrm{SD})$ & $(\chi \pm \mathrm{SD})$ & $<0.001^{* *}$ \\
\hline EDV $\mathbf{~ m L}$ & $103 \pm 18$ & $83 \pm 18$ & $<0.001^{* *}$ \\
\hline ESV mL & $66 \pm 13$ & $37 \pm 11$ & $0.00^{* *}$ \\
\hline Biplane EF \% & $35.6 \pm 5.19$ & $54.4 \pm 5.6$ & $0.00^{* *}$ \\
\hline WMSI & $2.23 \pm 0.2$ & $1.5 \pm 0.22$ &
\end{tabular}

$\mathbf{E D V}=$ end diastolic volume, $\mathbf{E S V}=$ end systolic volume, $\mathbf{E F}=$ ejection fraction, $\mathbf{W M S I}=$ wall motion score index, $\mathbf{m L}=$ milliliter

Table 7: Angiographic data in the study groups (I\&II)

\begin{tabular}{|c|c|c|c|}
\hline Variable & Group I $(n)=36$ & Group II (n) = 64 & P-value \\
\hline Single & $6(16.7 \%)$ & $39(60.9 \%)$ & \multirow{5}{*}{$0.00 * *$} \\
\hline \multirow{4}{*}{$\begin{array}{l}\text { Number of totally } \\
\text { diseased vessels }\end{array}$} & $14(38.9 \%)$ & $20(31.2 \%)$ & \\
\hline & $11(30.6 \%)$ & $3(4.7 \%)$ & \\
\hline & $4(11.1 \%)$ & $2(3.1 \%)$ & \\
\hline & $1(2.8 \%)$ & $0(0 \%)$ & \\
\hline \multirow{4}{*}{ Culprit artery } & $25(69.4)$ & $19(29.7 \%)$ & \multirow{4}{*}{$0.002 *$} \\
\hline & $3(8.3 \%)$ & $13(20.3 \%)$ & \\
\hline & $0(0 \%)$ & $1(1.6 \%)$ & \\
\hline & $8(22.2 \%)$ & $31(48.4 \%)$ & \\
\hline \multirow{2}{*}{\begin{tabular}{lc} 
No. of totally occluded & One \\
\cline { 2 - 2 } vessels including culprit & Two
\end{tabular}} & $34(94.4 \%)$ & $62(96.9 \%)$ & \multirow[t]{2}{*}{$0.5 \mathrm{NS}$} \\
\hline & $2(5.6 \%)$ & $2(3.1 \%)$ & \\
\hline Other significant vessels & $27(75 \%)$ & $15(23.4 \%)$ & $0.00 * *$ \\
\hline Culprit vessel severity $(\chi \pm$ SD) & $99.1 \pm 1.7$ & $97.23 \pm 12.5$ & $0.375 \mathrm{NS}$ \\
\hline Gensini score $(\chi \pm$ SD $)$ & $136.11 \pm 40.5$ & $87.9 \pm 31.31$ & $0.00 * *$ \\
\hline DBT $(\chi \pm$ SD $)$ & $80.7 \pm 22.23$ & $81.02 \pm 21.71$ & $0.939 \mathrm{NS}$ \\
\hline
\end{tabular}

A ROC curve was then constructed for significant continuous quantitative variables and area under the curve AUC, cut off point for every variable was determined as follows: figure 3

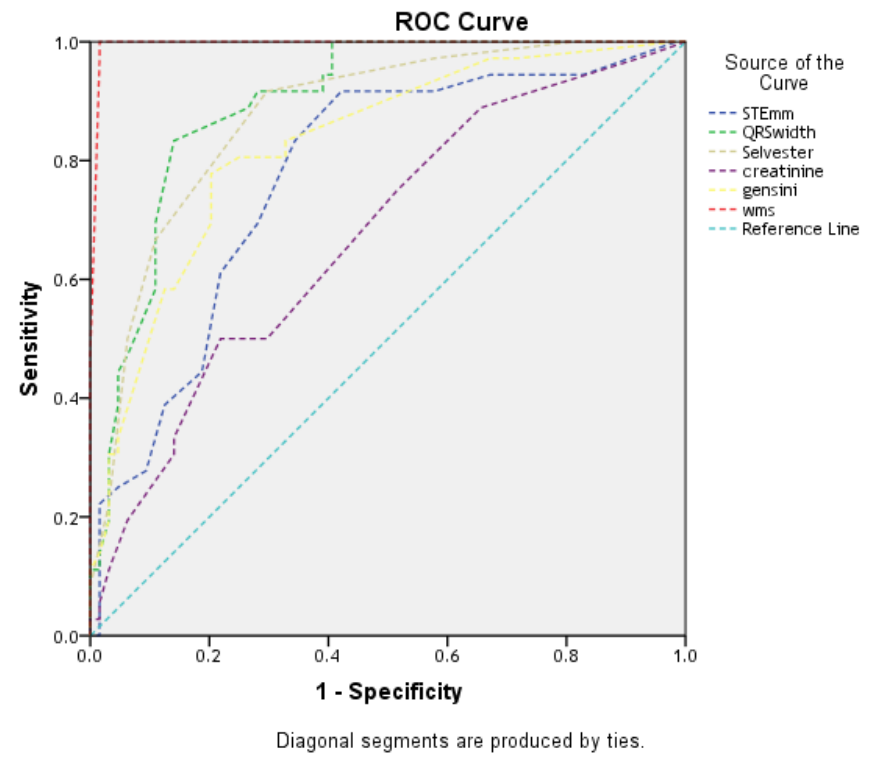

Figure 3: Significant quantitative continuous variables. 
By multivariate analysis, we found four significant independent predictors of depressed left ventricle function $(\mathrm{EF} \leq 40 \%)$. They were creatinine level $(p=0.029)$, total number of affected vessels $>2(\mathrm{p}=0.034)$, complete STR $>70 \%(\mathrm{p}=0.00)$ and WMSI $(\mathrm{p}=0.008)$.

A score then constructed containing both significant independent and dependent predictors.
Relative significance for each predictor given based on the significant predictor with the least value, each one of quantitative predictors was given the score if it was equal or above the cutoff point. A total score of 42 was then calculated (table 8)

Table 8: Score for prediction of depressed left ventricle function ( $\mathrm{EF} \leq 40 \%)$

\begin{tabular}{|c|c|}
\hline Variable & Score \\
\hline STE mm > $13.5 \mathrm{~mm}$ & +3 \\
\hline QRS width > $98.5 \mathrm{~ms}$ & +6 \\
\hline Selvester score $>\mathbf{3 . 5}$ & +4 \\
\hline Creatinine $>1.1 \mathrm{mg} / \mathrm{dl}$ & +1 \\
\hline No. of Total diseased vessels $>2$ & +3 \\
\hline Gensini score $>95$ & +4 \\
\hline WMSI > 2.05 & +11 \\
\hline Anterior infarction & +3 \\
\hline KILLIP > I & +1 \\
\hline Complete STR $<70$ & +6 \\
\hline Total score & +42 \\
\hline $\begin{array}{l}\text { To maximize clinical applicability, cut point } \\
\text { of } 21 \text { for prediction score was set. At cut point of } \\
>21 \text { (with higher scores representing a higher }\end{array}$ & $\begin{array}{l}\text { likelihood of having depressed left ventricle } \\
\text { function), test sensitivity was } 97.2 \% \text { and } \\
\text { specificity was } 98.4 \% \text {. Table } 9\end{array}$ \\
\hline
\end{tabular}

Table 9: Consistency of the predictive score at cut off point 21

\begin{tabular}{ccccccc}
\hline Sensitivity & specificity & + VE predictive & $\begin{array}{c}-\mathrm{VE} \\
\text { predictive }\end{array}$ & accuracy & $\begin{array}{c}\text { KAPPA } \\
\text { AGREEMENT }\end{array}$ & P \\
\hline $97.2 \%$ & $98.4 \%$ & $97.2 \%$ & $98.4 \%$ & $98 \%$ & 0.957 & $0.00^{* *}$ \\
\hline
\end{tabular}

A 3 tiered score was then constructed to divide patients in to 3 categories:

a) Low risk (score 0-14) with likelihood ratio of 2.9

b) Intermediate risk (score 15-28) with likelihood ratio of 2.1

c) high risk (score 29-42) with likelihood ratio of 2.4

\section{DISCUSSION}

The present study showed no statistical significant difference between the two groups as regard age and sex, hypertension $\mathrm{HTN}$, diabetes mellitus DM, smoking and dyslipidemia. This was concordant with Bhave et al. [6].

Regarding age, our study was discordant with Ali et al. [15] who stated that older age may predict LV dysfunction and heart failure in patients treated with thrombolysis for STEMI. This discrepancy could be explained by larger sample volume included in his study, higher mean age and different modalities of revascularization.

Regarding sex, our result was discordant with Shacham et al. [16]. In their study, they concluded that female patients demonstrated worse systolic and diastolic LV function, despite receiving similar treatment as male patients. This discrepancy could be explained by older females in their study and the co-morbidities they had in their study.

Regarding diabetes mellitus and smoking, our study was discordant with Mateus et al. [17]. They stated that a history of diabetes might be related to the likelihood of impaired LV systolic function. In addition, smoking increased the risk of left ventricular dysfunction compared to nonor ex-smokers. This discrepancy might be attributed to different point to define $\mathrm{LV}$ dysfunction (they used EF of $45 \%$ ). 
Our study showed no significant difference between the two groups regarding history of coronary artery disease (CAD); this was concordant with Świątkiewicz et al. [18] but was discordant with Bhave et al. [6]. In their study, a history of coronary artery disease was associated with a 3.1-fold increase in the odds of having depressed LV function ( $\mathrm{p}=0.014)$.

Our study showed no significant difference between the two groups regarding systolic blood pressure (SBP), diastolic blood pressure (DBP) and heart rate (HR). This was concordant with Hamdan et al. [19].

Regarding SBP, our result was discordant with Jia et al. [20]. In their study, SBP was an independent predictor of $\mathrm{LV}$ dysfunction in a multivariate regression analysis. Larger sample volume (850) might explain this discrepancy.

Regarding heart rate, our result was discordant with Honda et al. [21]. In 200 patients with myocardial infarction, heart rate on admission was a significant independent predictor of depressed LV function before discharge.

Regarding KILLIP class, KILLIP class II was higher in group I $(E F \leq 40 \%)(p=0.003)$. In a meta-analysis of three angioplasty trials on 2,654 acute myocardial infarction patients conducted by DeGeare et al. [22], their results were concordant with ours. They found that higher KILLIP class was associated with lower left ventricular ejection fraction $(\mathrm{p}<0.0001)$

Regarding need for mechanical ventilation (MV), we found significant difference between the 2 groups $(p=0.001)$ being more frequently encountered in group I. This was concordant with Bhave et al. [6] in which the need for mechanical ventilation was the strongest predictor of depressed LV function.

We found significant difference between the two groups regarding location of infarction ( $\mathrm{p}=$ 0.0002 ). Anterior infarction was more frequent in group I while inferior and anterolateral infarctions were more in group II. This was concordant with Świątkiewicz et al. [18]. This could be explained by the fact that anterior MI patients experience more pronounced post-infarction LV remodeling and dysfunction [23].

In our study, maximum ST segment elevation was significantly higher in group I with negative correlation with $\mathrm{EF}(\mathrm{r}=-0.398, \mathrm{p}<$ 0.001 ). This finding was in line with a previous study Bhave et al. [6]. This goes with the fact that the height of ST segment elevations may be a surrogate for the size of the myocardial territory being injured [6].
Regarding ST segment resolution, complete STR $>70 \%$ was significantly higher in group II $(\mathrm{p}<0.001)$ while partial and absent STR were higher in group I $(\mathrm{p}<0.001, \quad \mathrm{p}=0.006$ respectively).

Our result was concordant with that of Matetzky et al. [24]. They reported $28 \%$ left ventricular dysfunction rate in patients without ST resolution versus $19 \%$ in with ST resolution.

Our results were discordant to Kosuge et al. [25] in which clinical significance of ST resolution in 129 patients with anterior wall MI was evaluated and they found that ST resolution after recanalization does not consistently predict myocardial salvage in patients with anterior MI. This discrepancy may be due to their inclusion of anterior MI only which is known to have a larger area of myocardium affected and hence lower likelihood of ST resolution and improved LV function.

Regarding QRS width, QRS width was higher in-group I more than II $(\mathrm{p}<0.001)$ with significant negative correlation with $\mathrm{EF}(\mathrm{r}=$ $0.538, \mathrm{p}<0.001)$. This was concordant with Murkofsky et al. [26]. They showed that a prolongation of the QRS duration (>0.10 s) on a standard 12-lead ECG was associated with lower LV EF as determined by radionuclide gated blood pool imaging. This goes with the fact that increased QRS duration is associated with more advanced remodeling in patients with CAD and poor LV function [27].

On the other hand, in the sight of the Valsartan in acute myocardial infarction (VALIANT) trial, Yerra et al. [28] found that a prolonged QRS duration at baseline was associated with reduced systolic function. However, following adjustment for other variables, this association lost significance.

Regarding Selvester score, it was significantly higher in group I with a strong negative association with $\mathrm{EF}(\mathrm{r}=-0611, \mathrm{p}<0.001)$. This result was in agreement with Ghayal et al. [29]. They concluded that the ECG Selvester score was a better predictor of infarct size and reduced LVEF than cardiac biomarkers in patients undergoing primary PCI for STEMI. However, this was in disagreement with Adler et al. [30] in which they evaluated 51 patients with first anterior wall myocardial infarction who had received reperfusion therapy and pre discharge resting technetium - 99m - sestamibi scan. Overall, the correlation between the QRS score and the myocardial perfusion defect extent (rho $0.249 ; \mathrm{p}=0.08$ ) and ejection fraction (rho -0.229; $\mathrm{p}=0.11)$ was poor. 
In the present study, creatinine level was significantly higher in-group I $(p=0.007)$ with significant negative correlation with $\mathrm{EF}(\mathrm{r}=$ $0.296, p=0.003$ ). This was consistent with a previous study [6]. In their study, a baseline creatinine level of 1.0 to $1.5 \mathrm{mg} / \mathrm{dl}$ was associated with 2.4-fold increase in the odds of having depressed LV function compared to patients whose creatinine levels were $<1.0 \mathrm{mg} / \mathrm{dl}$.

Our result was discordant with a more recent study by $\mathbf{~ g g}$ et al. [31] in which creatinine showed no significant difference among 2648 STEMI patients divided in to three groups as regard LVEF ( $\mathrm{p}=0.5$ ). This might be explained by different modality in assessing renal impairment and different grouping as regard LVEF.

In our study, we found no significant difference between both groups regarding maximum creatine kinase (CK-MB) level. ( $\mathrm{p}=$ $0.15)$. This was in line with a study of Grande et al. [32] but was discordant with Turer et al. [33] in which correlation between peak CK-MB and both infarction size and EF was investigated. They concluded that $\mathrm{CK}-\mathrm{MB}$ values have significant correlation with both of them $(\mathrm{r}=-0.30, \mathrm{P}=$ 0.035). This discrepancy might be attributed to small sample size in our study compared to them and different modality in assessment of EF.

Regarding troponin level, we found no significant difference between our groups $(\mathrm{p}=0.63)$. This result was concordant with a previous study [6].

However, our results were in disagreement with that of Chia et al. [34] in which they found that a troponin I (Tn I) after 72 hours with threshold $>55 \mathrm{ng} / \mathrm{ml}$ was $90 \%$ sensitive for large infarct size $(\geq 10 \%)$ and low LVEF $(\leq 40 \%)$ $(\mathrm{p}=0.001)$. This discrepancy might be explained by their larger sample size (378 patients), different method in assessing LV function.

We found no significant difference between the two groups regarding admission random blood sugar $(\mathrm{p}=\mathbf{0 . 8 1})$. This result was in concordant with a previous study [6] but was in disagreement with that of Terlecki et al. [35] in which there was a significant difference as regard LV function between those with normoglycemia versus patients with hyperglycemia being lower in the latter group $(\mathrm{p}=0.0022)$. This might be due to higher number of patients included in their study, their lower value of defining hyperglycemia (140 $\mathrm{mg} / \mathrm{dl}$ versus $200 \mathrm{mg} / \mathrm{dl}$ in our study).

Regarding dyslipidemia, we found no significant difference between the 2 groups as regard LV function (cholesterol $\mathrm{p}=0.35$, TG $\mathrm{p}=$
0.19 , HDL $\mathrm{p}=0.96$, LDL $\mathrm{p}=0.96$ ). This was concordant with previous studies $[6,19]$.

On the other hand, in a study conducted by Mateus et al. [17] about impact of cardiovascular risk factors on LV function in STEMI patients, dyslipidemia was less common in patients with depressed LV function (35.4\% vs. $56.9 \%, \mathrm{p}=$ 0.01 ). This discrepancy might be higher percentage of dyslipidemic patients in depressed LV function group.

In our study, there was significant difference between the two groups regarding number of diseased vessels $(p<0.001)$ being higher in-group I with depressed LV function $(\mathrm{p}<0.001)$. This result was concordant with a study of Mateus et al. [17] and a recent study of Altmann et al. [36], this goes with the fact that increased number of affected vessels impairs perfusion of larger myocardial area and hence impair function [37].

On the contrary, our results were in disagreement with that of Hamdan et al. [19]. In their study, there was no significant difference regarding number of diseased vessels among STEMI patients stratified by EF. This discrepancy may be attributed to different way in stratifying patients as regard EF in to 3 groups (normal to mild, moderate and severe) with nearly comparable number of patients in all groups.

In our study, Culprit left anterior descending (LAD) was frequently encountered in group I $(\mathrm{EF} \leq 40 \%)$ while culprit left circumflex (LCX) and right coronary artery (RCA) were more in group II ( $\mathrm{EF} \geq 40 \%)$. This result was concordant with that of Altmann et al. [36], this goes with the fact that LAD supplies large myocardial area and its affection impairs perfusion of larger myocardial area and hence impair function [37].

In our study, there was significant difference between the two groups regarding Gensini score $(\mathrm{p}<0.001)$ with strong negative correlation with $\mathrm{EF}$ and high statistical significance $(\mathrm{r}=-0.53$, $\mathrm{p}<0.001)$. This was concordant with Jia et al. [20]. This goes with the fact of higher Gensini score is associated with more severe coronary artery disease, lower ST segment resolution and lower LV function [38].

There was significant difference between the two groups regarding wall motion score index (WMSI) being higher in group I ( $p<0.001)$ with strong negative correlation of high significance with $\mathrm{EF}$ ( $\mathrm{p}<0.001, \mathrm{r}=-0.99)$. This was concordant with Galasko et al. [39] in which 174 AMI were included and they found that WMSIs of 0.6, 0.8, and 1.1 corresponded best to EFs $45 \%, 40 \%$, and $35 \%$, respectively a greater degree of wall motion 
abnormality must take place before a lower EF occurs.

Our study demonstrated that decreased renal function (creatinine $>1.1 \mathrm{mg} / \mathrm{dl}$ ), increased total number of diseased vessels > 2, absence of complete ST segment resolution, wall motion score index $>2.05$, increased sum of ST segment elevation > $13.5 \mathrm{~mm}$, QRS width > $98.5 \mathrm{~ms}$, Selvester score $>3.5$, Gensini score > 95, anterior location of infarction and KILLIP class $>1$ are significant predictors of depressed LV function in patients presenting with STEMI.

A dichotomous prediction score created, with the goal of having high sensitivity for depressed LV function using a cutoff point 21 , was able to separate patients into 2 groups: very low risk for LV dysfunction and intermediate to high risk for LV dysfunction. Using a 3-tiered score categorization, discrimination among low-, intermediate-, and high-risk patients was possible.

Of 100 patients included in our study, 53 were considered as low risk patients (score 0-14) with likelihood of 2.9, 26 were considered moderate risk (score 15-28) with likelihood ratio of 2.1 and 21 considered as high risk patients (score 29-42) with likelihood ratio of 2.4.

\section{Study limitation:}

1- Small sample size of our study. This could limit the generalizability of our findings.

2- The results obtained from a single medical center (Zagazig University hospital)

3- Selection bias may present because of exclusion of few patients who did not do echocardiography during their index hospitalization.

4- Lack of long term follow up of left ventricle function so that we could not detect possible LV function recovery with time.

5- Our study applied on STEMI only, excluding NSTEMI and unstable Angina.

6- We did not take in to consideration SYNTAX score in assessing severity of coronary artery disease.

\section{CONCLUSION}

Our findings may aid in the clinical management of patients with STEMI in the early stages of their hospitalization. Studies have shown that early beta-blockers administration, a therapy long considered the standard of care in the emergency department for STEMI, decreases the risk for arrhythmia and re-infarction but at the cost of a significant increase in the incidence of cardiogenic shock. Therefore,

A high prediction score for LV dysfunction may identify patients who are likely to have more harm than benefit from early aggressive therapy. In contrast, patients with low prediction scores could be targeted as better candidates for such therapy.

\section{REFERENCES}

1. Jernberg T, Johanson P, Held C, Svennblad B, Lindbäck J, Wallentin L, \& SWEDEHEART/RIKS-HIA (2011). Association between adoption of evidence-based treatment and survival for patients with ST-elevation myocardial infarction, JAMA: the journal of the American Medical Association 305, 1677-1684.

2. Golabchi A, Sadeghi M, Sanei H, Akhbari MR, Seiedhosseini SM, Khosravi P, \& Alisaeedi AR (2010). Can timi risk score predict angiographic involvement in patients with st-elevation myocardial infarction?, ARYA atherosclerosis 6, 69-73.

3. Antoni ML, Boden H, Delgado V, Boersma E, Fox K, Schalij MJ, \& Bax JJ (2012). Relationship between discharge heart rate and mortality in patients after acute myocardial infarction treated with primary percutaneous coronary intervention, European heart journal 33, 96-102.

4. Gao Z, Xu B, Yang Y-J, Kandzari DE, Yuan J-Q, Chen J, Chen J-L, Qiao S-B, Wu Y-J, Yan H-B, Qin X-W, Yao M, Liu H-B, Dai J, Chen T, Teng S-Y, \& Gao R-L (2012). Clinical and angiographic correlates of left ventricular dysfunction in patients with three vessel coronary disease, Chinese medical journal 125, 4221-4225.

5. Andrassy M, Volz HC, Riedle N, Gitsioudis G, Seidel C, Laohachewin D, Zankl AR, Kaya Z, Bierhaus A, Giannitsis E, Katus HA, \& Korosoglou G (2011). HMGB1 as a predictor of infarct transmurality and functional recovery in patients with myocardial infarction, Journal of internal medicine 270, 245-253.

6. Bhave PD, Hoffmayer KS, Armstrong EJ, Garg S, Patel A, Macgregor JS, Stein JC, Kinlay S, Ganz P, \& McCabe JM (2012). Predictors of depressed left ventricular function in patients presenting with ST-elevation myocardial infarction, The American journal of cardiology 109, 327-331.

7. Schröder R (2004). Prognostic impact of early STsegment resolution in acute ST-elevation myocardial infarction, Circulation 110, e506-510.

8. Strauss DG, \& Selvester RH (2009). The QRS complex--a biomarker that 'images' the heart: QRS scores to quantify myocardial scar in the presence of normal and abnormal ventricular conduction, Journal of electrocardiology 42, 8596.

9. Lang RM, Bierig M, Devereux RB, Flachskampf FA, Foster E, Pellikka PA, Picard MH, Roman MJ, Seward J, Shanewise JS, Solomon SD, Spencer KT, Sutton MSJ, Stewart WJ, Chamber Quantification Writing Group, American Society of Echocardiography's Guidelines and Standards Committee, \& European Association of Echocardiography (2005). Recommendations for 
chamber quantification: a report from the American Society of Echocardiography's Guidelines and Standards Committee and the Chamber Quantification Writing Group, developed in conjunction with the European Association of Echocardiography, a branch of the European Society of Cardiology, Journal of the American Society of Echocardiography: official publication of the American Society of Echocardiography 18, 1440-1463.

10. Schiller NB, Shah PM, Crawford M, DeMaria A, Devereux R, Feigenbaum H, Gutgesell H, Reichek N, Sahn D, \& Schnittger I (1989). Recommendations for quantitation of the left ventricle by two-dimensional echocardiography. American Society of Echocardiography Committee on Standards, Subcommittee on Quantitation of Two-Dimensional Echocardiograms, Journal of the American Society of Echocardiography: official publication of the American Society of Echocardiography 2, 358367.

11. Lebeau R, Serri K, Morice M-C, Hovasse T, Unterseeh T, Piéchaud J-F, \& Garot J (2012). Assessment of left ventricular ejection fraction using the wall motion score index in cardiac magnetic resonance imaging, Archives of Cardiovascular Diseases 105, 91-98.

12. Ergelen M, Uyarel H, Osmonov D, Ayhan E, Akkaya E, Soylu O, Orhan AL, Sayar N, Bozbay M, Turer A, Yildirim E, \& Yekeler I (2010). Early stent thrombosis in patients undergoing primary coronary stenting for acute myocardial infarction: incidence, a simple risk score, and prognosis, Clinical and applied thrombosis/hemostasis: official journal of the International Academy of Clinical and Applied Thrombosis/Hemostasis 16, 33-41.

13. Gensini GG (1983). A more meaningful scoring system for determining the severity of coronary heart disease, The American journal of cardiology $51,606$.

14. Sullivan DR, Marwick TH, \& Freedman SB (1990). A new method of scoring coronary angiograms to reflect extent of coronary atherosclerosis and improve correlation with major risk factors, American heart journal 119, 12621267.

15. Ali AS, Rybicki BA, Alam M, Wulbrecht N, Richer-Cornish K, Khaja F, Sabbah HN, \& Goldstein S (1999). Clinical predictors of heart failure in patients with first acute myocardial infarction, American heart journal 138, 11331139.

16. Shacham Y, Topilsky Y, Leshem-Rubinow E, Laufer-Perl M, Keren G, Roth A, Steinvil A, \& Arbel Y (2014). Comparison of Left Ventricular Function Following First ST-Segment Elevation Myocardial Infarction Treated With Primary Percutaneous Coronary Intervention in Men Versus Women, The American journal of cardiology
17. Mateus PS, Dias CC, Betrencourt N, Adão L, Santos L, Sampaio F, Mateus C, Primo J, Simões L, Barros H, \& Ribeiro VG (2005). Left ventricular dysfunction after acute myocardial infarction--the impact of cardiovascular risk factors, Revista portuguesa de cardiologia: orgão oficial da Sociedade Portuguesa de Cardiologia = Portuguese journal of cardiology: an official journal of the Portuguese Society of Cardiology 24, 727-734.

18. Świątkiewicz I, Magielski P, Woźnicki M, Gierach J, Jabłoński M, Fabiszak T, Koziński M, Sukiennik A, Bronisz A, \& Kubica J (2012). Occurrence and predictors of left ventricular systolic dysfunction at hospital discharge and in long-term follow-up after acute myocardial infarction treated with primary percutaneous coronary intervention, Kardiologia polska 70, 329-340.

19. Hamdan A, Kornowski R, Solodky A, Fuchs S, Battler A, \& Assali AR (2006). Predictors of left ventricular dysfunction in patients with first acute anterior myocardial infarction undergoing primary angioplasty, The Israel Medical Association journal: IMAJ 8, 532-535.

20. Jia E-Z, Xu Z-X, Yang Z-J, Zhu T-B, Wang L-S, Cao K-J, \& Ma W-Z (2011). Severity of coronary atherosclerosis is an independent predictor of the left ventricular ejection fraction, Clinical and experimental pharmacology \& physiology 38, $109-112$

21. Honda T, Kanazawa H, Koga H, Miyao Y, \& Fujimoto K (2010). Heart rate on admission is an independent risk factor for poor cardiac function and in-hospital death after acute myocardial infarction, Journal of Cardiology 56, 197-203.

22. DeGeare VS, Boura JA, Grines LL, O’Neill WW, \& Grines CL (2001). Predictive value of the Killip classification in patients undergoing primary percutaneous coronary intervention for acute myocardial infarction, The American journal of cardiology 87, 1035-1038.

23. Masci PG, Ganame J, Francone M, Desmet W, Lorenzoni V, Iacucci I, Barison A, Carbone I, Lombardi M, Agati L, Janssens S, \& Bogaert J (2011). Relationship between location and size of myocardial infarction and their reciprocal influences on post-infarction left ventricular remodelling, European heart journal 32, 16401648.

24. Matetzky S, Novikov M, Gruberg L, Freimark D, Feinberg M, Elian D, Novikov I, Di Segni E, Agranat O, Har-Zahav Y, Rabinowitz B, Kaplinsky E, \& Hod H (1999). The significance of persistent ST elevation versus early resolution of ST segment elevation after primary PTCA, Journal of the American College of Cardiology 34, 1932-1938.

25. Kosuge M, Kimura $\mathrm{K}$, Ishikawa $\mathrm{T}$, Endo $\mathrm{T}$, Sugano T, Hibi K, Nakagawa T, Nakatogawa T, Saito T, Okuda J, Tochikubo O, \& Umemura S (2002). Reliability of resolution of ST-segment elevation after coronary reperfusion in predicting 
myocardial salvage in anterior wall acute myocardial infarction, The American Journal of Cardiology 90, 227-232.

26. Murkofsky RL, Dangas G, Diamond JA, Mehta D, Schaffer A, \& Ambrose JA (1998). A prolonged QRS duration on surface electrocardiogram is a specific indicator of left ventricular dysfunction [see comment], Journal of the American College of Cardiology 32, 476-482.

27. De Winter O, Van de Veire N, Van Heuverswijn F, Van Pottelberge G, Gillebert TC, \& De Sutter J (2006). Relationship between QRS duration, left ventricular volumes and prevalence of nonviability in patients with coronary artery disease and severe left ventricular dysfunction, European journal of heart failure 8, 275-277.

28. Yerra L, Anavekar N, Skali H, Zelenkofske S, Velazquez E, McMurray J, Pfeffer M, \& Solomon SD (2006). Association of QRS duration and outcomes after myocardial infarction: the VALIANT trial, Heart Rhythm: The Official Journal of the Heart Rhythm Society 3, 313-316.

29. Ghayal P, Mathur A, Hashim H, Raskin A, Di Giorgio C, Mazza V, Maher J, Gerula C, \& Klapholz M (2014). Predictive value of selvester score in estimating infarct size in patients undergoing primary percutaneous coronary intervention, Journal of the American College of Cardiology 63, A153.

30. Adler Y, Zafrir N, Ben-Gal T, Lulu OB, Maynard C, Sclarovsky S, Balicer R, Mager A, Strasberg B, Solodky A, Wagner GS, \& Birnbaum Y (2000). Relation between evolutionary ST segment and Twave direction and electrocardiographic prediction of mycardial infarct size and left ventricular function among patients with anterior wall Q-wave acute myocardial infarction who received reperfusion therapy, The American journal of cardiology 85, 927-933.

31. Ng VG, Lansky AJ, Meller S, Witzenbichler B, Guagliumi G, Peruga JZ, Brodie B, Shah R, Mehran R, \& Stone GW (2013). The prognostic importance of left ventricular function in patients with ST-segment elevation myocardial infarction: the HORIZONS-AMI trial, European Heart Journal: Acute Cardiovascular Care, 2048872613507149.

32. Grande P, Nielsen A, Wagner GS, \& Christiansen C (1985). Quantitative influence of serum creatine kinase isoenzyme MB estimated infarct size and other prognostic variables on one-year mortality after acute myocardial infarction. British Heart Journal 53, 9-15.

33. Turer AT, Mahaffey KW, Gallup D, Weaver WD, Christenson RH, Every NR, \& Ohman EM (2005). Enzyme estimates of infarct size correlate with functional and clinical outcomes in the setting of ST-segment elevation myocardial infarction, Current controlled trials in cardiovascular medicine 6, 12.

34. Chia S, Senatore F, Raffel OC, Lee H, Wackers FJT, \& Jang I-K (2008). Utility of cardiac biomarkers in predicting infarct size, left ventricular function, and clinical outcome after primary percutaneous coronary intervention for ST-segment elevation myocardial infarction, JACC. Cardiovascular interventions 1, 415-423.

35. Terlecki M, Bednarek A, Kawecka-Jaszcz K, Czarnecka D, \& Bryniarski L (2013). Acute hyperglycaemia and inflammation in patients with ST segment elevation myocardial infarction, Kardiologia polska 71, 260-267.

36. Altmann DR, Mutschelknauss M, Ehl N, Koller M, Schaer B, Jörg L, Ammann P, Kühne M, Rickli H, Osswald S, \& Sticherling C (2013). Prevalence of severely impaired left ventricular ejection fraction after reperfused ST-elevation myocardial infarction, Swiss medical weekly 143, w13869.

37. De Luca G, Gibson M, Cutlip D, Huber K, Dudek D, Bellandi F, Noc M, Maioli M, Zorman S, Zeymer U, Secco GG, Mesquita Gabriel H, Emre A, Arntz H-R, Rakowski T, Gyongyosi M, Hof AWJV, \& EGYPT Cooperation (2013). Impact of multivessel disease on myocardial perfusion and survival among patients undergoing primary percutaneous coronary intervention with glycoprotein IIb/IIIa inhibitors, Archives of cardiovascular diseases 106, 155-161.

38. Esen Zencirci A, Zencirci E, Degirmencioglu A, Karakus G, Ugurlucan M, Gunduz S, Ozden K, Erdem A, Karadeniz F, Ekmekci A, Erer H, Sayar N, \& Eren M (2014). The relationship between Gensini score and ST-segment resolution in patients with acute ST-segment elevation myocardial infarction undergoing primary percutaneous coronary intervention, Kardiologia polska

39. Galasko GI, Basu S, Lahiri A, \& Senior R (2001). A prospective comparison of echocardiographic wall motion score index and radionuclide ejection fraction in predicting outcome following acute myocardial infarction, Heart (British Cardiac Society) 86, 271-276. 